\title{
Analysis of the impact of metal thickness and geometric parameters on the quality factor- $Q$ in integrated spiral inductors by means of artificial bee colony technique
}

\author{
Hamid Bouyghf ${ }^{1}$, Bachir Benhala ${ }^{2}$, Abdelhadi Raihani ${ }^{3}$ \\ ${ }^{1,3}$ LSSDIA, ENSET Mohammedia, University of Hassan II Casablanca, BP 159 Bd Hassan II-Mohammedia-Morocco \\ ${ }^{2}$ BABA Team, LEAB, Faculty of Sciences, University Moulay Ismail, BP 11201, Zitoune, Meknes-Morocco
}

\begin{tabular}{|c|c|}
\hline Article Info & ABSTRACT \\
\hline & \multirow{10}{*}{$\begin{array}{l}\text { The goal of this present paper is to design, analysis the influence of the } \\
\text { inductor geometrical parameters and the effect of the metal thickness on the } \\
\text { quality factor-Q in integrated square spiral inductor using an efficient } \\
\text { application of the artificial bee colony (ABC) algorithm. The inductors were } \\
\text { optimized at } 2.4 \mathrm{GHz} \text { to determinate their major geometrical dimensions (sp, } \\
\mathrm{w}, d_{i n . . .} \text { ) and their number of turns, for uses in radio-frequency integrated } \\
\text { circuits (RFICs). The optimization results are validated by the simulation } \\
\text { using an electromagnetic simulator (ADS-Momentum). Using matlab } \\
\text { software, the study on the impact of the effect of geometrical parameters and } \\
\text { the effect of metal thickness, on the factor of quality-Q of spiral inductors, is } \\
\text { shown. We first reported that it is possible to improve Q-factors further by } \\
\text { increasing the metal thickness, and in the design of inductor; a compromise } \\
\text { must be reached between the value of } \mathrm{w}, \mathrm{n} \text {, sp and } \operatorname{din}_{\text {in }} \text { to achieve the desired } \\
\text { quality factor-Q and other electrical parameters. }\end{array}$} \\
\hline Received Oct 10, 2018 & \\
\hline Revised Mar 29, 2019 & \\
\hline Accepted Apr 3, 2019 & \\
\hline Keywords: & \\
\hline $\mathrm{ABC}$ algorithm & \\
\hline Metal thickness & \\
\hline Optimization & \\
\hline Quality factor-Q & \\
\hline RFICs & \\
\hline
\end{tabular}

Spiral inductor

\section{Corresponding Author:}

Hamid Bouyghf,

LSSDIA, ENSET Mohammedia,

University of Hassan II Casablanca,

BP 159 Bd Hassan II-Mohammedia-Morocco.

Email: hamid.bouyghf@gmail.com
Copyright $@ 2019$ Institute of Advanced Engineering and Science. All rights reserved.

\section{INTRODUCTION}

Planar spiral CMOS inductors have become significant element and important passive components in many circuit blocks used in telecommunication applications and radio frequency (RF) transceivers. The square spiral inductor design space is complex, and new optimization and synthesis techniques are required to realize practical designs and layouts [1]. Major analog/RF circuits like Voltage Controlled Oscillators (VCO), Mixers, Filters, RF Amplifiers and Low Noise Amplifiers (LNAs), strongly depend on inductors with optimized design parameters. Consequently, the efficient optimization methodology of spiral inductors is critical to the successful realization of telecommunication systems.

Historically, most of research and papers on spiral inductor optimization techniques have concentrated on the maximizing the inductor's quality factor (Q) for a fixed operating frequency and desired inductance value. To efficiently resolve this issue, some swarm intelligence algorithms were proposed in the literature $[2,3]$ and are used by the analog/RF engineers. These algorithms focus on swarm or group of animal behavior in order to develop some meta-heuristics which can mimic their problem resolution abilities, such as Particle Swarm Optimization (PSO) [4], Ant Colony Optimization (ACO) [5-7] and, recently, Artificial Bee Colony (ABC) [8-10].

Artificial Bee Colony (ABC) is a new optimization technique proposed by (Karaboga) in 2005 [11]. It is a population based stochastic optimization algorithm inspired by the intelligent collective foraging behavior observed in the bee colony. It has inspired from the organizational nature and foraging behavior of 
honeybee swarms. Subsequently, we focus on the use of an Artificial Bee Colony (ABC) to the optimal sizing of RF CMOS spiral inductors. In this paper, spiral inductor is optimized and simulated using ABC algorithm and ADS-Momentum software, respectively. We have also studied the influence of the effect of the geometric parameters and the metal thickness on the quality factor-Q.

\section{OVERVIEW OF ARTIFICIAL BEE COLONT (ABC) ALGORITHM}

The $\mathrm{ABC}$ has inspired from the organizational nature and foraging behavior of honeybees [11]. In the $\mathrm{ABC}$ algorithm, the bee colony comprises three kinds of bees: employed bees, onlooker bees, and scout bees. Each bee has a specialized task in the colony to maximize the nectar amount that is stored in the hive. In $\mathrm{ABC}$, each food source is placed in the D-dimensional search space and represents a potential solution to the optimization problem. The amount of nectar in the food source is assumed to be the fitness value of a food source. Generally, the number of employed and onlooker bees is the same and equal to the number of food sources. Each employed bee belongs to a food source and is responsible for mining the corresponding food source. Then, employed bees pass the nectar information to onlooker bees in the "dance area." Onlooker bees wait in the hive and select a food source to mine based on the information coming from the employed bees. Here, more beneficial food sources will have higher selection probabilities to be selected by onlooker bees.

In $A B C$, in order to decide if a food source is abandoned or not, trial counters and a predetermined limit parameter are used. If a solution represented by a food source does not improve during a number of trials (limit), the food source is abandoned. When the food source is abandoned, the corresponding employed bees will become scout bees and randomly generate a new food source and replace it with the abandoned one. The onlooker bees evaluate the nectar information and choose a food source depending on the probability value associated with that food source using the Equation (1) [12]:

$$
p_{i}=\frac{\text { fit } i}{\sum_{j=1}^{3 N} \text { fit }_{j}}
$$

where fit $_{i}$ is the solution's fitness value $\mathrm{i}$, which in turn is proportional to the amount of nectar of the source of food in the position $\mathrm{i}$ and $\mathrm{SN}$ is the number of food sources which is equal to the number of employed bees in the colony [12]. On their turn, the onlooker bees also employ the same process of modification and selection of the food positions as the employed bees do. This can be demonstrated by the Equation (2).

$$
V_{i, j}^{n e w}=x_{i, j}^{o i d}+\Phi_{i, j}\left(x_{i, j}^{o i d}-x_{k, j}^{o i d}\right)
$$

where $j$ is a randomly selected index $j \in\{1,2 \ldots D\}$ and $k \in\{1,2 \ldots S N\}$ is a randomly chosen food source that is not equal to $i$; that is, $(k \neq i) . \phi_{i, j}$ is a random number within the range $[-1,1]$ generated specifically for each $i$ and $j$ combination. This controls the generation of the neighborhood food sources. A greedy selection is applied between $X_{i}$ and $V_{i}$ by selecting the better one. When the food-source position has been abandoned, the employed bee associated with it becomes a scout. The scout produces a completely new food source position as using Equation (2). Generally, the ABC algorithm steps can be summarized as shown in Figure 1 [13]: 


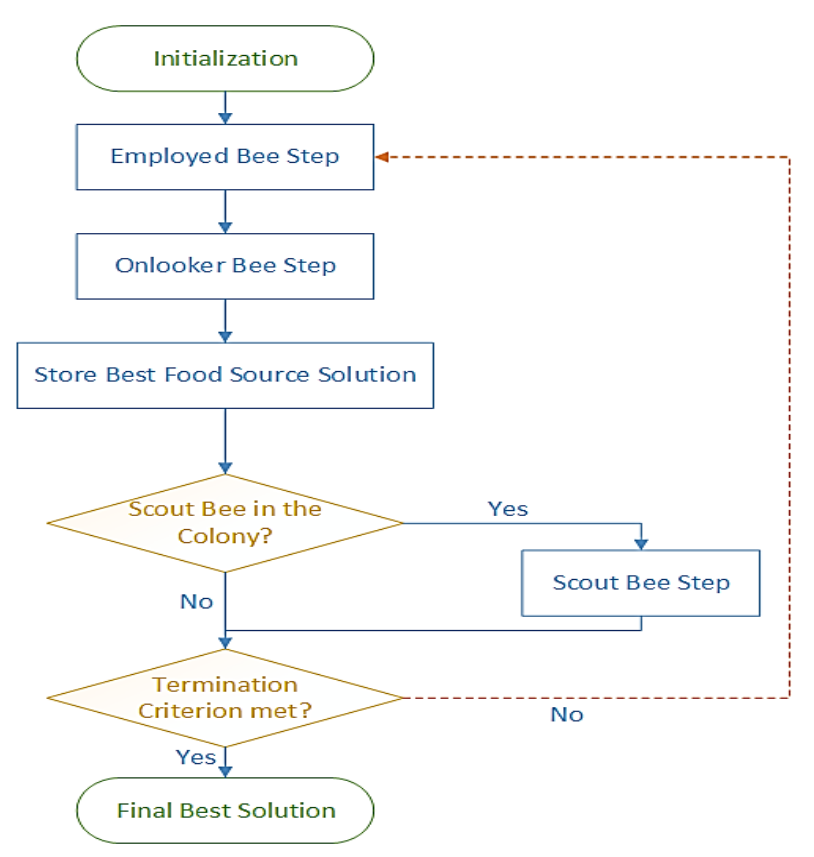

Figure 1. Artificial bee colony algorithm flow chart

It is clear, from the above explanation, that in the ABC algorithm, there are four control parameters used: The number of the food sources that is equal to the number of employed or onlooker bees (SN), the value of limit and the maximum cycle number $(\mathrm{MCN})$.

\section{ANALYSIS OF THE RFIC SPIRAL INDUCTORS}

\subsection{Layout variables for optimization}

Figure 2 shows the layout of square spiral inductor. The geometry parameters characterizing the spiral inductor are the number of turns (n), the trace width (w), the turn spacing (sp), and the inner diameter $\left(\mathrm{d}_{\text {in }}\right)$. $\left(\mathrm{d}_{\text {out }}\right)$ is outer diameter.

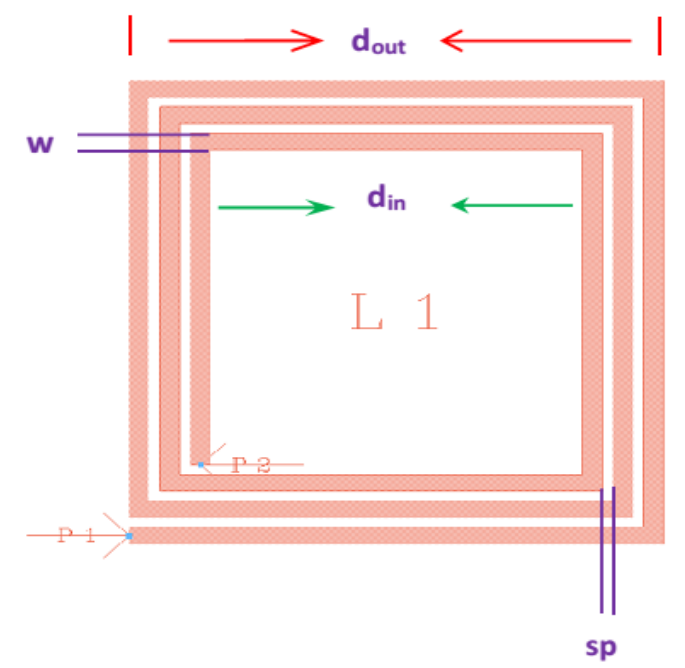

Figure 2. The geometry parameters of a square spiral inductor

In our study case, we focus on the application of $\mathrm{ABC}$ algorithm for optimization the geometric parameters of spiral inductors. 


\subsection{Analysis of the spiral inductor model}

The physical model of spiral inductor on silicon is a very popular model used in microelectronic RF design [14]. Its model parameter values can be expressed directly using the geometry of the spiral inductor. An approach is developed in [15] to direct parameter extraction based on the measured two-port S-parameters.

Figure 3 presents the equivalent circuit model of the inductor, the model parameters are $R s, R s i, C s$, Cox, Csi and Ls. Where Ls is the inductance of the spiral, Cox represents the capacitance between the spiral and the silicon substrate. Rsi and Csi model the resistance and the capacitance of the substrate respectively, and Cs models the parallel-plate capacitance between the spiral and the centertap underpass. However, we have considered the simplified equivalent circuit shown in Figure 4 to calculate the inductance value. Therefore, the inductance value for a given frequency (f) is determined by Equation (3) [16]:

$$
L_{\mathrm{s}}=-\frac{1}{2 \pi \mathrm{f}} \operatorname{Im}\left(\frac{1}{\mathrm{Y}_{\mathrm{i} 2}}\right)
$$

Thereafter, we will use this equation to calculate the inductance using Y-parameter obtained from ADS Momentum software.

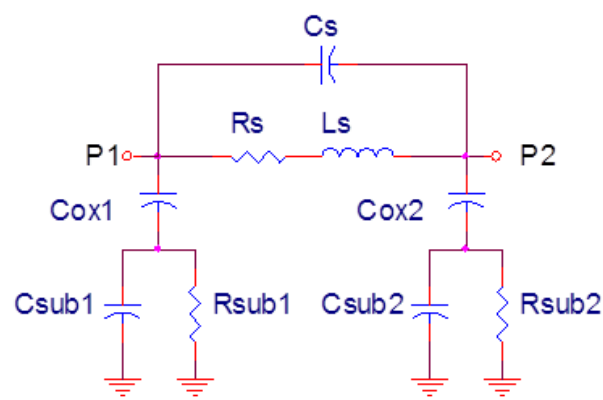

Figure 3. Physical model of a spiral inductor $[17,18]$

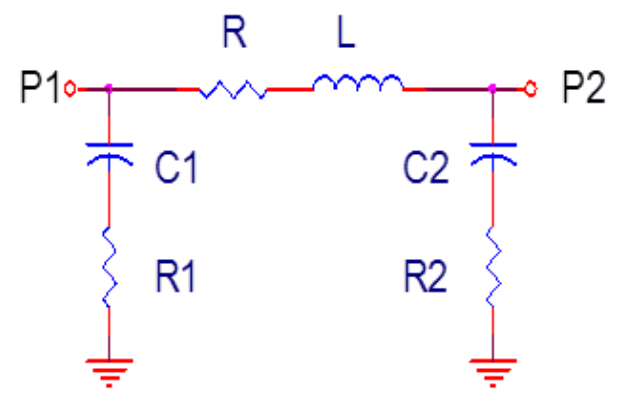

Figure 4. Simplified equivalent circuit for calculating inductance value

where $C s u b 1=C s u b 2=C s i$ and $R s u b 1=R s u b 2=R s i$

The parameters $R s, R s i, C s, C o x$ and $C s i$ are defined by the following equations [14]:

$$
\begin{aligned}
& R_{s}=\frac{l}{w \cdot \sigma \cdot \delta \cdot\left(1-e^{-t / \delta}\right)} \\
& R_{s i}=\frac{2}{l \cdot w \cdot G_{s u b}} \\
& C_{s}=n \cdot w^{2} \cdot \frac{\varepsilon_{o x}}{t_{o x M} 1-M 2} \\
& C_{o x}=\frac{1}{2} \cdot l \cdot w \cdot \frac{\varepsilon_{o x}}{t_{o x}} \\
& C_{s i}=\frac{1}{2} \cdot l \cdot w \cdot C_{s u b} \\
& \delta=\sqrt{\frac{2}{\omega \mu} \sigma}
\end{aligned}
$$


where $\sigma$ is the metal conductivity at $\mathrm{dc}, \delta$ is the metal skin depth, $\mathrm{t}$ is the metal thickness, $t_{o x M 1-M 2}$ is the oxide thickness between spiral and centertap, $t_{o x}$ is the oxide thickness between spiral and substrate, 1 is the overall length of spiral, w is the line width, $G_{s u b}$ is the substrate conductance per unit area, and $C_{\text {sub }}$ is the substrate capacitance per unit area.

The parallel equivalent circuit of spiral inductor shown in Figure 5 is used for calculation the quality factor $(\mathrm{Q})$ of the inductor [18]:

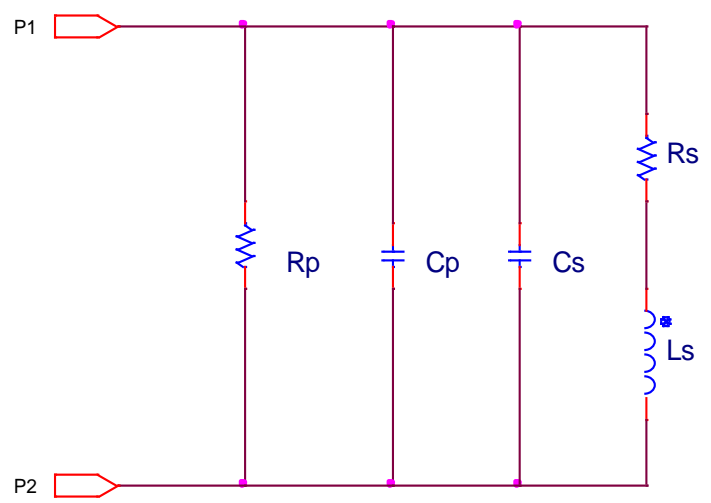

Figure 5. The parallel equivalent circuit of the spiral inductor [18]

The quality factor (Q) can be expressed as [18]:

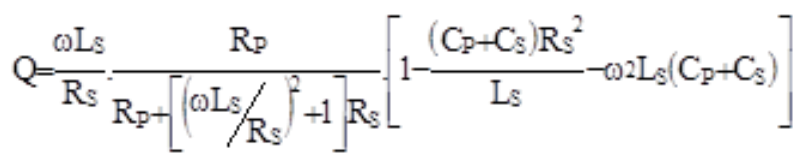

where

$$
\begin{aligned}
& \mathrm{R}_{\mathrm{p}}=\frac{1}{\omega{ }^{2} \mathrm{C}_{\mathrm{ax}}{ }^{2} \mathrm{R}_{\mathrm{i}}}+\mathrm{R}_{\mathrm{iz}}\left(1+\mathrm{C}_{\mathrm{gi}} / \mathrm{C}_{\mathrm{ax}}\right)^{2} \\
& \mathrm{C}_{\mathrm{P}}=\mathrm{C}_{\mathrm{ox}} \frac{1+\omega^{2}\left(\mathrm{C}_{\mathrm{ax}}+\mathrm{C}_{\mathrm{Si}}\right) \mathrm{C}_{\mathrm{Si}} \mathrm{R}_{\mathrm{gi}}{ }^{2}}{1+\omega^{2}\left(\mathrm{C}_{\mathrm{ax}}+\mathrm{C}_{\mathrm{Si}}\right)^{2} \mathrm{R}_{\mathrm{gi}}{ }^{2}}
\end{aligned}
$$

The quality factor can also be calculated from the Y-parameters as [16]:

$$
Q=-\frac{\operatorname{Im}\left(Y_{11}\right)}{\operatorname{Re}\left(Y_{11}\right)}
$$

We will use (13) to calculate the quality factor using the Y-parameter obtained from ADS Momentum software. The inductance Ls is modeled by the following monomial expression [17, 18]:

$$
L_{s}=\beta \cdot d_{\text {out }}^{\alpha} \cdot w^{\alpha} \cdot d_{\text {avg }}^{\alpha_{3}} \cdot n^{\alpha} \cdot 4 \cdot p^{\alpha} \cdot 5
$$

where

$$
\begin{aligned}
& d_{\text {avg }}=1 / 2 \cdot\left(d_{\text {out }}+d_{\text {in }}\right) \\
& d_{\text {out }}=d_{\text {in }}+2 \cdot n \cdot w+2 \cdot(n-1) \cdot s p
\end{aligned}
$$

$\beta$ and $\alpha_{i}(i=1,2 \ldots 5)$ are the coefficients depend on the inductor topology. The coefficients for square inductor are [19]: $\beta=1.62 \mathrm{e}-3, \alpha_{1}=-1.21, \alpha_{2}=-0.147, \alpha_{3}=2.4, \alpha_{4}=1.78, \alpha_{5}=-0.03$ 


\section{OPTIMIZATION METHODOLOGY FOR INDUCTOR DESIGN}

\subsection{Problem formulation}

The ABC optimization method is executed on a vector of design variables of RF circuit. In fact, the bee position vector is the $\mathrm{x}_{1}, \mathrm{x}_{2}, \ldots \mathrm{x}_{\mathrm{d}}$ design variables of circuit. At first, each bee (i-th bee) position vector is randomly initialized. In each iteration, the $\mathrm{ABC}$ algorithm runs the programme for each bee and evaluates a Cost Function (CF), described in the form of a posynomial function with inequality constraints expressed as posynomial functions and equality constraints as monomial functions [20]:

A monomial function has the following form:

$$
g\left(x_{1}, \ldots, x_{a}\right)=B x_{1}^{a_{1}} x_{2}^{a_{2}} x_{3}^{a_{3}} \ldots . . x_{a}^{a}
$$

where $B$ is a positive constant $(B>0), x_{1}, x_{2} \ldots$ and $x_{n}$ are real positive variables: $a_{1}, a_{2} \ldots$ and $a_{n}$ are constants known as the exponents of the monomial. Any positive constant is a monomial. Monomials are closed under multiplication and division. A posynomial function is a sum of one or more monomial functions as shown in the following equation (CF obtained by equivalent circuit analysis of RF circuit):

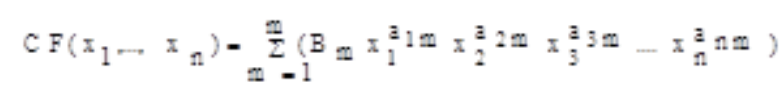

So, the design problem of the spiral inductor can be formulated as:

Maximize of Q-quality factor (Minimize $\mathrm{Q}_{\mathrm{req}}$ ): [Cost Function (CF) is done by (10)]

Subject to

$$
\begin{aligned}
& \mathrm{Q} \geq \mathrm{Q}_{\text {Lmin }} \\
& \mathrm{L}_{\mathrm{s}}=\mathrm{L}_{\text {saq }}: \text { Required inductance }
\end{aligned}
$$

Independent geometry parameters constraints may be added such as:

a. Number of turn : $\mathrm{n} \leq 4$

b. Minimum value of the track width: $\mathrm{w} \leq 12 \mu \mathrm{m}$

c. Minimum of spacing: $\mathrm{sp}=2.5 \mu \mathrm{m}$

d. Outer diameter: $\mathrm{d}_{\mathrm{in}} \leq 145 \mu \mathrm{m}$

For reducing the parasitic effect due to the proximity problem [21], we will respect this add constraint:

$$
d_{\text {in }}>5 . w \text { and } 0.2<\left(d \text { in } / d_{\text {out }}\right)<0.8
$$

The object function finds the global minimum CF for its expression:

$$
\mathrm{CF}=\mathrm{Q} \text { rsq }+1.0 \mathrm{e} 9 * \mathrm{abs}\left(\mathrm{L}_{\mathrm{s}}-\mathrm{L}_{\mathrm{sreq}}\right)+\text { penalty } * \mathrm{Sum}(\mathrm{Ct})
$$

where $\mathrm{Q}_{\mathrm{req}}=1 / \mathrm{Q}$, Penalty: Penalty of each constraint violation, Sum $(\mathrm{Ct})$ : Some of all constraints (Ct (1), Ct (2)...). Equation (20) is the minimum value of ObjVal (CF) guarantees the maximal value for $\mathrm{Q}$-factor for Lsreq $=4 \mathrm{nH}$ and $\mathrm{F}_{\text {req }}=\mathrm{f}_{\mathrm{s}}=2.4 \mathrm{GHz}$. The technological parameters are summarized in Table 1 for UMC 130nm CMOS technology.

Algorithm control parameters are given in Table 2. The number of iterations is equal to 1000. For the spiral inductor design, the $\mathrm{ABC}$ algorithm starts with creation of the initial bees by randomization, where each bee is composed by four design variables [ $\left.d_{i n}=\operatorname{Bee}(:, 1), w=\operatorname{Bee}(:, 2), \operatorname{sp}=\operatorname{Bee}(:, 3), n=\operatorname{Bee}(:, 4)\right]$, representing the layout geometry parameters, and must obey to variable boundaries (upper and lower boundaries). 
Table 1. Technological parameters for inductor design

\begin{tabular}{ccc}
\hline Name & Symbol & Value \\
\hline Metal thickness & $t$ & $2.8 \mathrm{e}-6$ \\
Thickness of the oxide insulator between the spiral and & $t_{\mathrm{oxM} 1 \mathrm{M} 2}$ & $0.4 \mathrm{e}-6$ \\
underpass t 6 M1-M2 & $t_{\mathrm{ox}}$ & $5.42 \mathrm{e}-6$ \\
Thickness of the oxide & $\sigma$ & $1 / 2.65 \mathrm{e}-8$ \\
Metal conductivity & $G_{\text {sub }}$ & $2.43 \mathrm{e} 5$ \\
Substrate conductance Gsub & $E_{\mathrm{ox}}$ & $3.453 \mathrm{e}-11$ \\
Permitivity of the oxide & $t_{\text {sub }}$ & $700 \mathrm{e}-6$ \\
Substrate thickness & $\rho$ & $28 \Omega \mathrm{cm}$ \\
Substrate resistivity & $\varepsilon \mathrm{r}$ & 11.9 \\
Substrate permitivity & $\mathrm{u}(\mathrm{mju})$ & $\mathbf{1 . 2 5 6 e - 6}$ \\
\hline
\end{tabular}

Table 2. ABC control parameters for inductor design

\begin{tabular}{cc}
\hline Parameter name & Value \\
\hline Colony size (CS) & 100 \\
Number of Onlookers bees & $50 \%$ of The swarm \\
Number of Employed bees & $50 \%$ of The swarm \\
Number of Food sources & $\mathrm{CS} / 2$ \\
\hline
\end{tabular}

\subsection{Optimization results}

The design and simulation results of $4 \mathrm{nH}$ inductor for an operation frequency of $2.4 \mathrm{GHz}$ are addressed using UMC 130nm CMOS technology parameters shown in Table 1. The ABC optimization results are done and verified with using an EM simulator (Momentum-ADS) [22]. A maximum tolerance $\delta$ and relative error of $4 \%$ respectively are assumed and accepted. Table 3 gives the results obtained by ABC. Figure 6 gives the cost function versus number of iterations. Figure 7 shows the Momentum-ADS simulation results $(\mathrm{Q}$ and $\mathrm{L})$ using the obtained optimal values by $\mathrm{ABC}$-based method [8] for RF CMOS square spiral inductor.

Table 3. Optimization results obtained by $\mathrm{ABC}$ algorithm

\begin{tabular}{ccccccccc}
\hline $\mathrm{sp}(\mu \mathrm{m})$ & $\mathrm{d}_{\text {in }}(\mu \mathrm{m})$ & $\mathrm{w}(\mu \mathrm{m})$ & $\mathrm{n}$ & $\mathrm{d}_{\text {out }}(\mu \mathrm{m})$ & $\mathrm{L}_{\text {req }}(\mathrm{nH})$ & $\mathrm{L}_{\mathrm{ABC}}(\mathrm{nH})$ & $\delta(\%)$ & $\mathrm{Q}_{\mathrm{ABC}}$ \\
\hline 2.5 & 140.45 & 11.15 & 3.5 & 231 & 4 & 3.96 & 1 & 12.71 \\
\hline
\end{tabular}

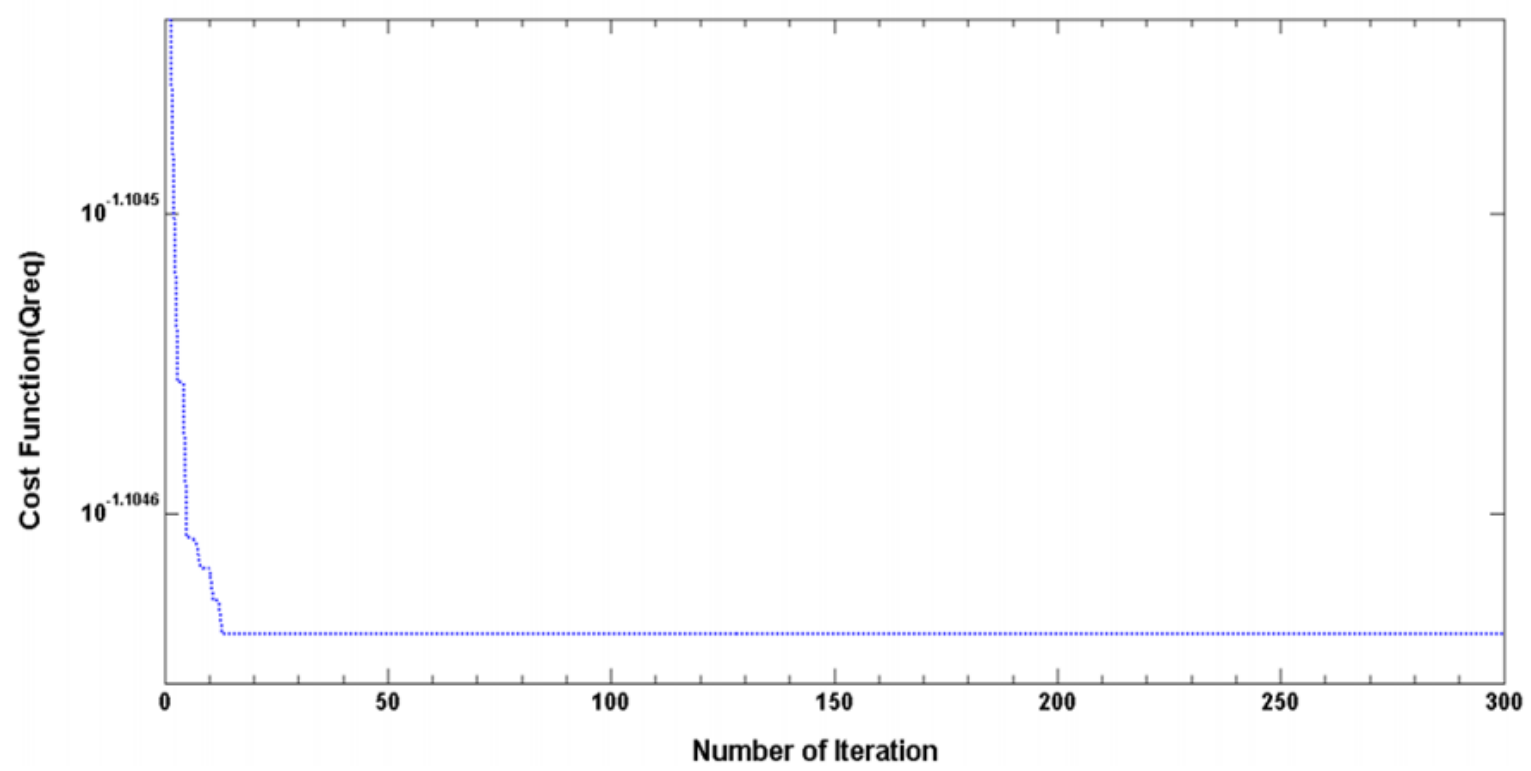

Figure 6. Cost function of the spiral inductor versus Iterations 

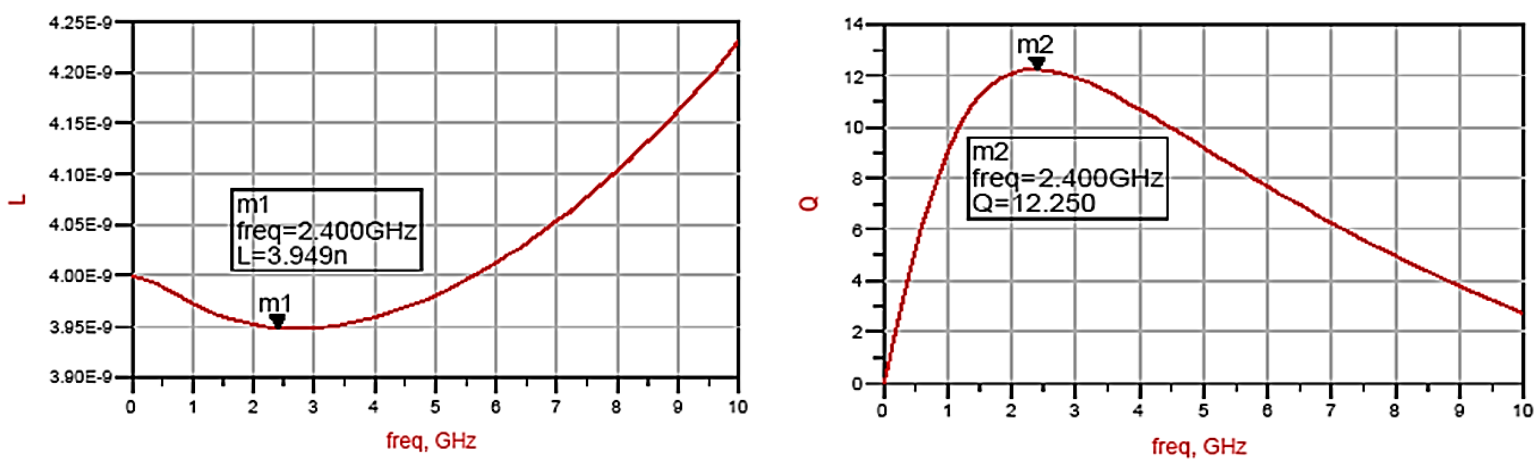

Figure 7. Momentum-ADS simulations for L and Q

We notice that the simulation results are in good agreement with those obtained using the ABC technique. Table 4 shows the comparison of results between evaluated and simulated with electromagnetic simulator.

Table 4. Comparison of optimized and simulated results

\begin{tabular}{cccccc}
\hline $\mathrm{L}_{\mathrm{ABC}}(\mathrm{nH})$ & $\mathrm{L}_{\text {Mom. }}{ }^{*}(\mathrm{nH})$ & Error $_{(\mathrm{L})}(\%)$ & $\mathrm{Q}_{\mathrm{ABC}}$ & Q $_{\text {Mom. }}{ }^{*}$ & Error $_{(\mathrm{Q})}(\%)$ \\
\hline 3.96 & 3.95 & 0.25 & 12.71 & 12.25 & 3.75 \\
\hline
\end{tabular}

\section{INFLUENCE OF THE GEOMETRIC PARAMETERS AND METAL THICKNESS ON THE QUALITY FACTOR-Q}

This section will study the impact ofgeometric parameters and metal thickness of inductors, on the factor ofquality by the exploiting of the optimized result obtained as shown in Table 3. For the study of each one, the parameter to be studied has been varied.

\subsection{Impact of the geometric parameters of inductor on the factor of quality}

In order to analyzethe influence that the geometric parameters of the inductor have on the quality factor-Q behavior, we use matlab software for simulations with exploiting of the optimization results shown in Table 3. While varying number of turns (n), the trace width (w), spacing between tracks (sp), and the inner diameter $\left(\mathrm{d}_{\mathrm{in}}\right)$, reasons of changes in the quality factor-Q behavior of inductor are analyzed in detail for each case. The maximum $\mathrm{Q}\left(\mathrm{Q}_{\max }\right)$ and self-resonance frequency $(\mathrm{SFR})$ are easily extracted from the curve of $\mathrm{Q}$ versus frequency.

\subsubsection{Separation between tracks: sp}

To analysis the variation of this parameter on the factor of quality, six inductor types are chosen for simulation, all these inductors have the same geometrical parameters except for separation between tracks (sp). The $\mathrm{w}=11.15 \mathrm{um}, \mathrm{d}_{\mathrm{in}}=140.45 \mathrm{um}$, and the number of turns $\mathrm{n}=3.5$. As the spacing between tracks varying from 1.5 to $4 \mathrm{um}$, the performance of the spiral inductors is shown in Figure 8 and Table 5.

Figure 8 and Table 5 show that the maximum quality factor-Qmax decreases with the increase of the spacing sp. As the sp decreases, the substrate coupling has no clear change, so the changes of Freq (Qmax) and SRF are not clear. The reason for the decrease of $\mathrm{Q}_{\max }$ in that the increase of the spacing between adjacent metal traces lowers the magnetic coupling of the metal traces. 


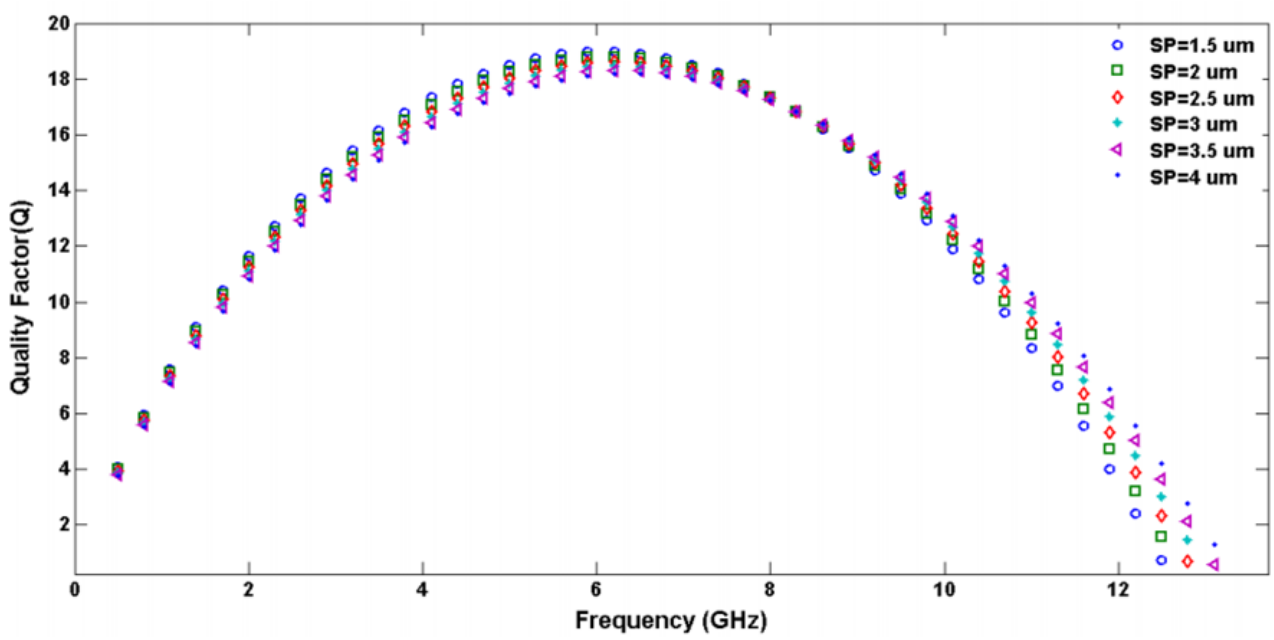

Figure 8. Simulation results of quality factor for different values of $\mathrm{sp}$

Table 5. Results of simulation for different values of $\mathrm{sp}$

\begin{tabular}{ccccc}
\hline Inductor & $\mathrm{Sp}(\mathrm{um})$ & $\mathrm{Q}_{\max }$ & Freq/Q & \\
\hline 1 & 1.5 & 18.98 & 6.2 & $\mathrm{SRF}(\mathrm{GHz})$ \\
2 & 2 & 18.79 & 6.2 & 12.62 \\
3 & 2.5 & 18.62 & 6.2 & 12.79 \\
4 & 3 & 18.46 & 6.2 & 12.96 \\
5 & 3.5 & 18.31 & 6.2 & 13.07 \\
6 & 4 & 18.18 & 6.5 & 13.2 \\
\end{tabular}

\subsubsection{Trace width: $w$}

In this study, we intend to compare the effect of the variation of the track width for six inductor types with the w parameter taking values from 6.15 to $11.15 \mu \mathrm{m}$. The $\mathrm{sp}=2.5 \mathrm{um}, \mathrm{n}=3.5$, and $\mathrm{d}_{\text {in }}=140.45 \mathrm{um}$. Figure 9 and Table 6 illustrate the performance of the spiral inductors for different trace widths. Figure 9 shows that, for the simulated inductor, as increases the width of the track of the spiral, the quality factor increases its value. However, it is appreciated that the inductance is reduced, since the enclosed area in the spiral is smaller. In addition, the resonance frequency decreases due to evident increase in parasitic capacities.

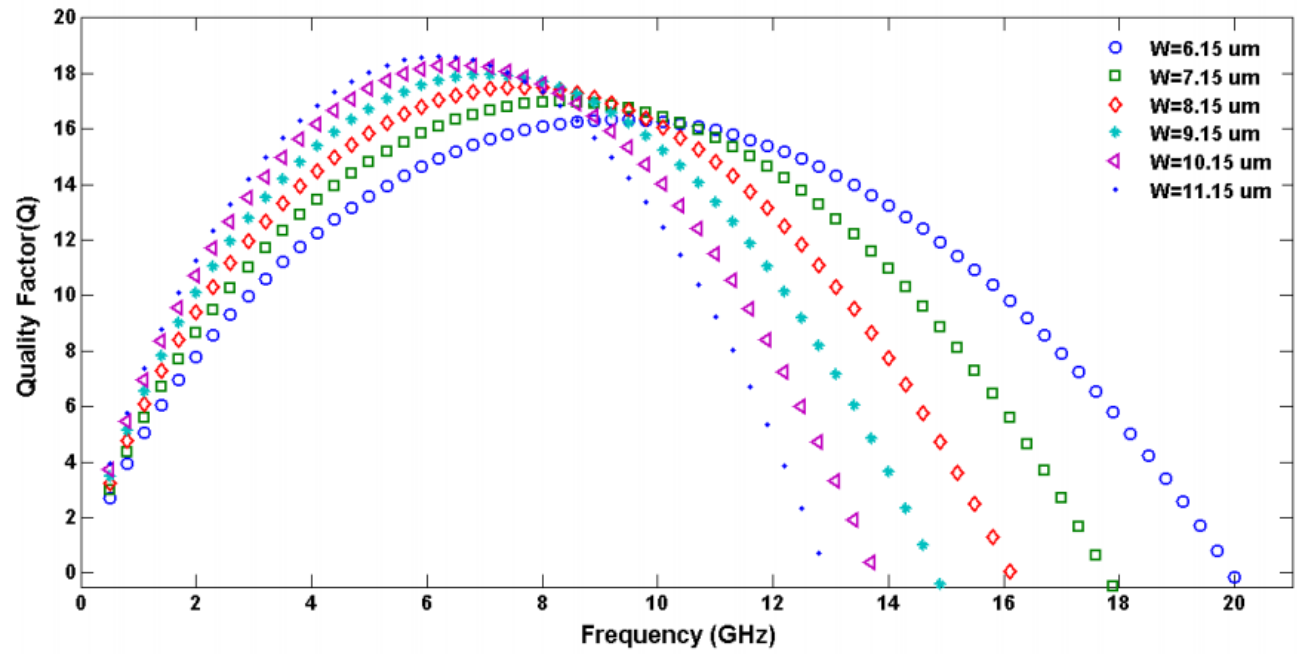

Figure 9. Simulation results of quality factor for different values of w 
Table 6. Results of simulation for different values of $\mathrm{w}$

\begin{tabular}{ccccc}
\hline Inductor & $\mathrm{w}(\mathrm{um})$ & $\mathrm{Q}_{\max }$ & Freq/Q $\max (\mathrm{GHz})$ & $\mathrm{SRF}(\mathrm{GHz})$ \\
\hline 1 & 6.15 & 16.2 & 9.5 & 20 \\
2 & 7.15 & 16.84 & 8.3 & 17.8 \\
3 & 8.15 & 17.5 & 7.4 & 16.1 \\
4 & 9.15 & 17.94 & 6.8 & 14.85 \\
5 & 10.15 & 18.27 & 6.5 & 13.8 \\
6 & 11.15 & 18.62 & 6.2 & 12.96 \\
\hline
\end{tabular}

\subsubsection{Number of turns: $n$}

The six inductor types have been simulated for a value of number of turns (n) varying from 1.5 to 4 with step equal to 0.5 . The $\mathrm{d}_{\mathrm{in}}=140.45 \mathrm{um}, \mathrm{sp}=2.5 \mathrm{um}$ and $\mathrm{w}=11.15 \mathrm{um}$. Figure 10 and Table 7 illustrates the performance of spiral inductors for different values of number of turns (n). We can see clearly that, for increasing the number of turns, the SRF and Qmax decreases. When the number of turns increases, then metal loss and substrate coupling increased, this is the reason for the decrease of Qmax and SRF.

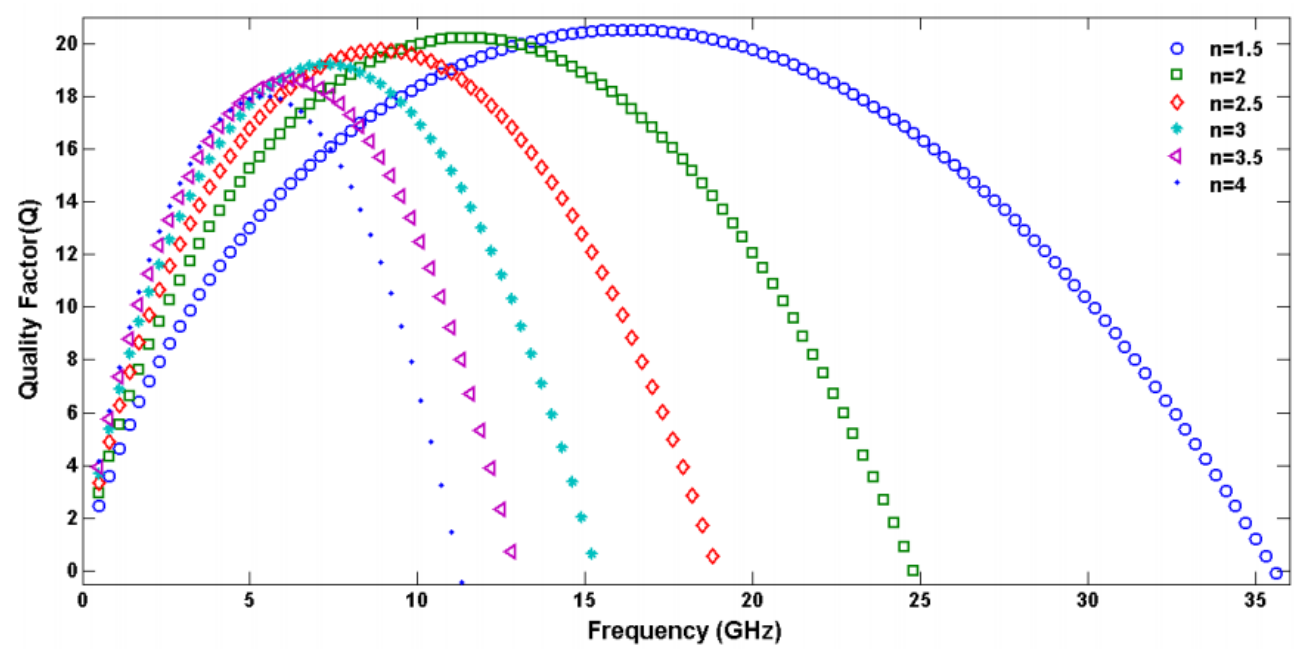

Figure 10. Simulation results of quality factor for different values of $n$

Table 7. Results of simulation for different values of $n$

\begin{tabular}{ccccc}
\hline Inductor & $\mathrm{n}$ & $\mathrm{Q}_{\max }$ & Freq/Q & max \\
\hline 1 & 1.5 & 20.52 & 16.1 & $\mathrm{SRF}(\mathrm{GHz})$ \\
2 & 2 & 20.19 & 11 & 35.4 \\
3 & 2.5 & 19.73 & 8.6 & 24.8 \\
4 & 3 & 19.15 & 7.7 & 18.6 \\
5 & 3.5 & 18.62 & 6.2 & 15.1 \\
6 & 4 & 18 & 5.6 & 12.96 \\
\hline
\end{tabular}

\subsubsection{Variation of inner diameter: $d_{\text {in }}$}

The six-inductor types have been simulated with different $d_{\text {in }}$ values. The $s p=2.5 \mathrm{um}, \mathrm{w}=11.15 \mathrm{um}$ and $n=3.5$. The performance of integrated spiral inductors for $d_{i n}$ from $140.45 u m$ to 190.45 um with step equal to 10um is illustrated in Figure 11 and Table 8.

Inner diameter $\left(\mathrm{d}_{\mathrm{in}}\right)$ has been varied from 140.45 to $190.45 \mu \mathrm{m}$. As the Inner diameter of spiral inductors is increased, self-resonant frequency of inductor decreases significantly. As the $d_{\text {in }}$ decreases, the proximity effect becomes significant enough to introduce an eddy current in the metal traces, consequently increasing the series resistance [23, 24]. 


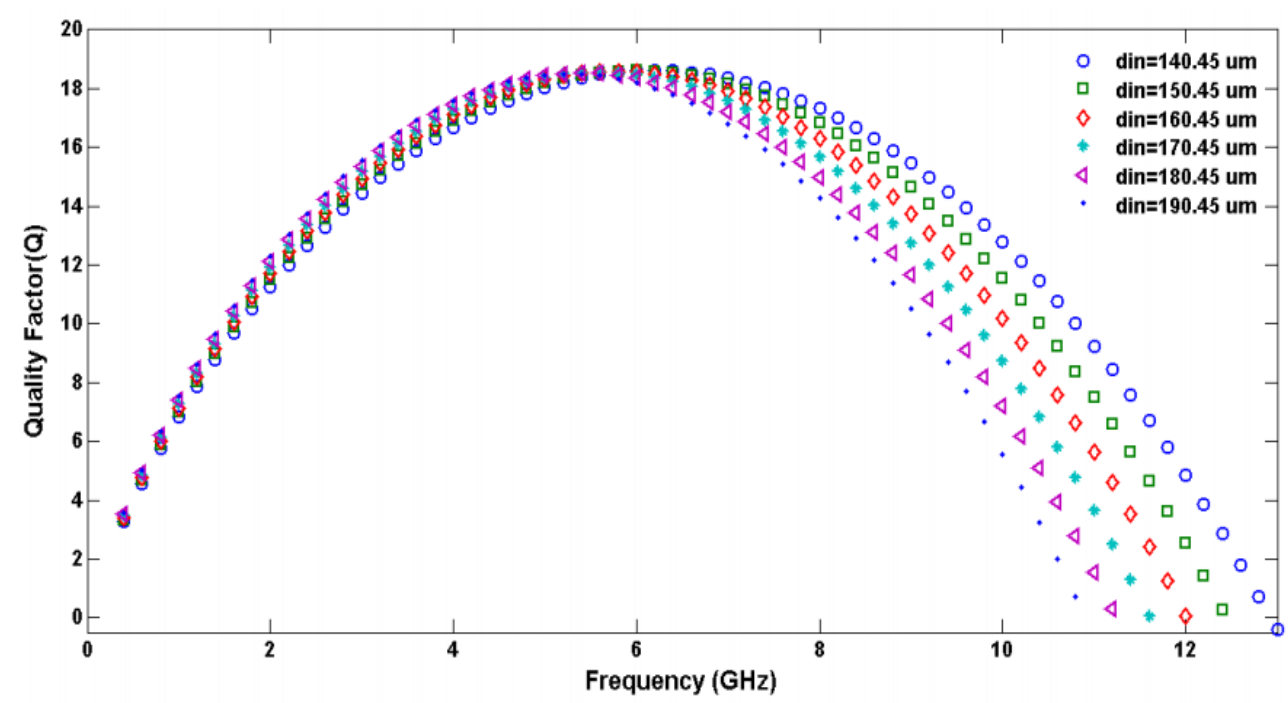

Figure 11. Simulation results of quality factor for different values of $d_{\text {in }}$

Table 8. Results of simulation for different values of $d_{\text {in }}$

\begin{tabular}{ccccc}
\hline Inductor & $\mathrm{d}_{\text {in }}(\mathrm{um})$ & $\mathrm{Q}_{\max }$ & Freq/Qmax $(\mathrm{GHz})$ & $\mathrm{SRF}(\mathrm{GHz})$ \\
\hline 1 & 140.45 & 18.62 & 6.2 & 12.96 \\
2 & 150.45 & 18.61 & 6 & 12.45 \\
3 & 160.45 & 18.59 & 5.8 & 12 \\
4 & 170.45 & 18.56 & 5.6 & 11.61 \\
5 & 180.45 & 18.53 & 5.4 & 11.25 \\
6 & 190.45 & 18.50 & 5.2 & 10.9 \\
\hline
\end{tabular}

\subsubsection{Analysis of the effect of metal thickness $t$ on Q-factor}

By varying the metal thickness from 1.9 to $3.9 \mathrm{um}$, the Q-factor can be increased because of the reduced series resistance caused by increased metal sidewall areas of current. However, there is insignificant shift in the self-resonant frequency. Figure 12 shows the effect of increasing thickness of metal on quality factor-Q.

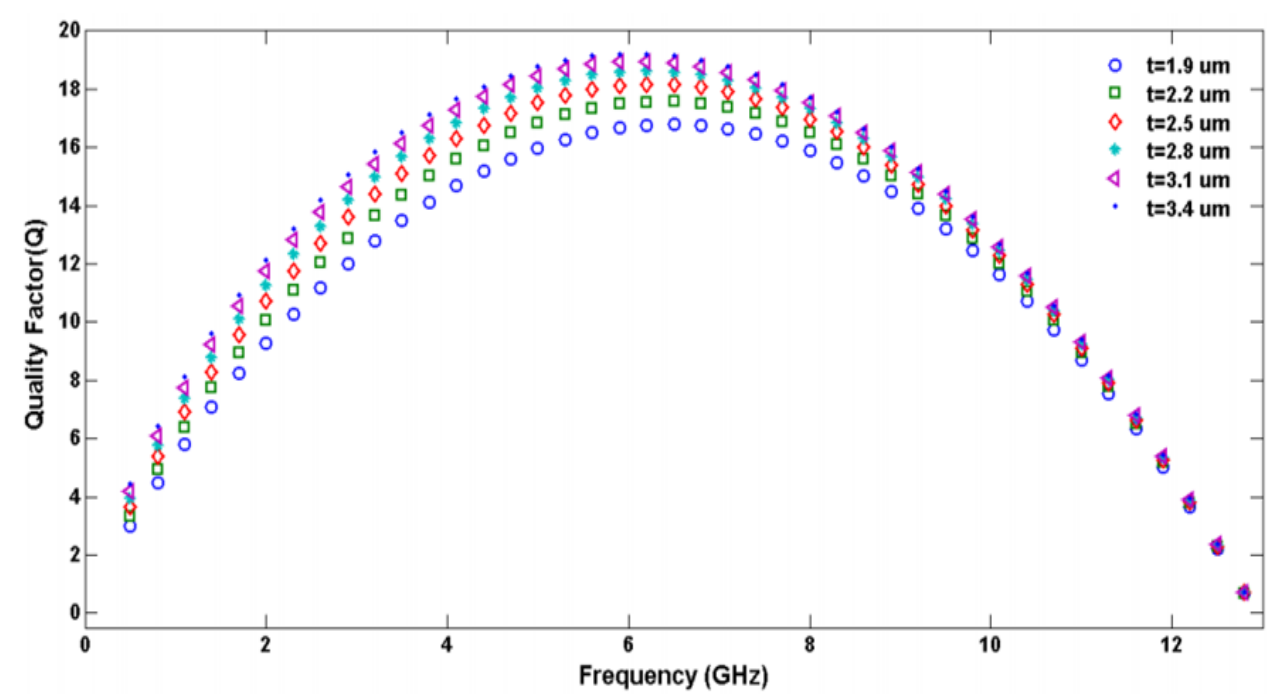

Figure 12. Variation of inductor's quality factor with frequency at different thickness 
At lower frequencies, increasing the metal thickness decreases the series resistance as can be observed from Figure 13, due to increase in cross section of the metal. This results in higher quality factor with increasing thickness. As the frequency increases, skin and proximity effects cause an increase in series resistance [25].

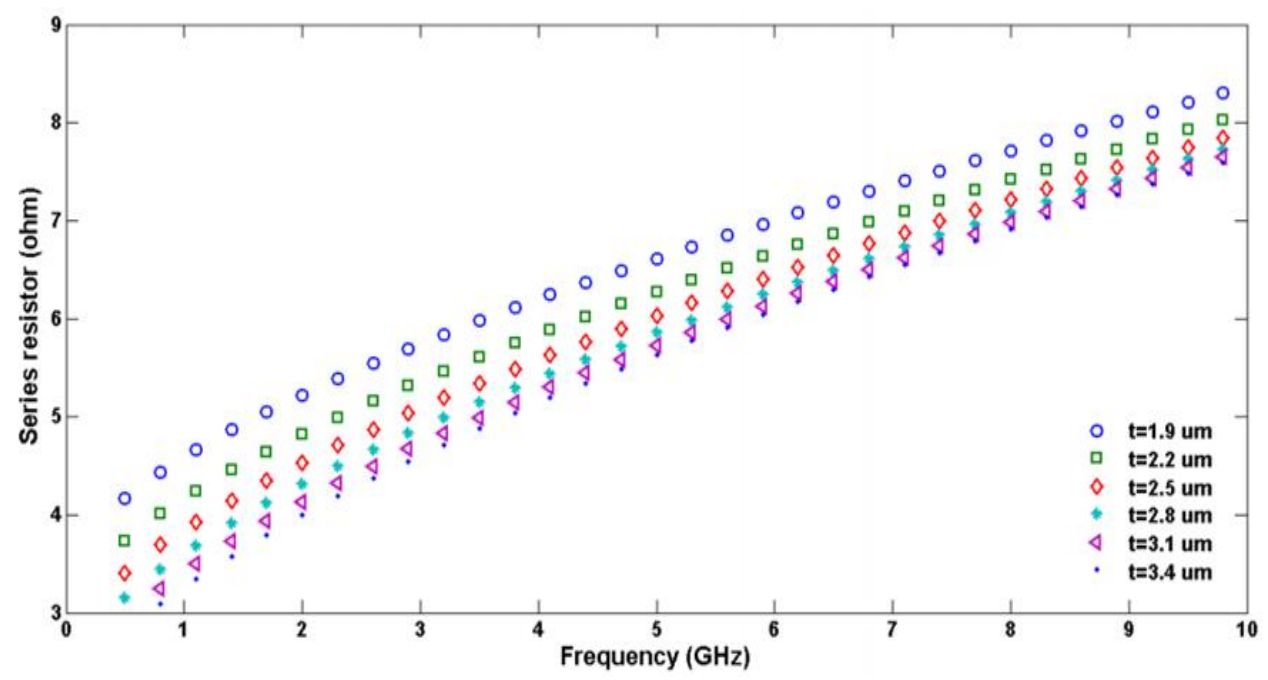

Figure 13. Variation of inductor's series resistance with frequency at different values of metal thickness

\section{CONCLUSION}

In this work, we have presented the design optimization of integrated square spiral inductor based on posynomial expression of quality factor-Q by taking consideration of design requirements and constraints. The comparison of performances by the ABC based method and those obtained by Momentum-ADS is in good accuracy, with error below to $4 \%$. In other, from the results of the section 5 , we can reach various conclusions that are reflected in Table 9. In the design inductors are must compromise between the value of $\mathrm{w}, \mathrm{n}, \mathrm{sp}$ and $\mathrm{d}_{\mathrm{in}}$ to reach the desired factor of quality-Q.

Table 9. Summary of the section 5

\begin{tabular}{|c|c|c|}
\hline Parameters & Qmax & $\mathrm{SRF}(\mathrm{GHz})$ \\
\hline$\hat{T}_{\mathrm{n}}$ & $\downarrow$ & $\downarrow$ \\
\hline & $\hat{\top}$ & \\
\hline$\hat{T}_{\mathrm{sp}}$ & Insignificant & $\hat{\top}$ \\
\hline$\widehat{\widehat{T}} \mathrm{~d}_{\mathrm{in}}$ & Insignificant & $\downarrow$ \\
\hline
\end{tabular}

\section{REFERENCES}

[1] A. Nieuwoudt and Y. Massoud, "Multi-level Approach for Integrated Spiral Inductor Optimization," Proceedings of the IEEE/ACM Design Automation Conference, DAC 05, pp. 648-651, 2005.

[2] I. H. Osman and J. P. Kelly, "Metaheuristics theory and applications," Kluwers Academic Publishers, Boston, 1996.

[3] E. H. L. Aarts and J. K. Lenstra, "Local search in combinatorial optimization," Princeton: Princeton University Press, 2003.

[4] M. Fakhfakh, et al., "Analog Circuit Design Optimization through the Particle Swarm Optimization Technique," Analog Integrated Circuits and Signal Processing, vol/issue: 63(1), pp. 71-82, 2010. 
[5] B. Benhala, "Ant Colony Optimization for Optimal Low-Pass Butterworth Filter Design," WSEAS Transactions on Circuits and Systems, vol. 13, pp. 313-318, 2014.

[6] B. Benhala, “An Improved ACO Algorithm for the Analog Circuits Design Optimization," International Journal of Circuits, Systems and Signal Processing, vol. 10, pp. 128-133, 2016.

[7] B. Benhala, et al., "Backtraching ACO for RF-Circuit Design Optimization," Performance Optimization Techniques in Analog, Mixed-Signal, and Radio Frequency Circuit Design, in M. Fakhfakh, et al., IGI-Global, Chapter 7, pp. 158-179, 2014.

[8] H. Bouyghf, et al., "Optimal Design of RF CMOS Circuits by Means of an Artificial Bee Colony Technique," Focus on Swarm Intelligence Research and Applications, in B. Benhala, et al., Nova Science Publishers,Chapter 11, pp. 221-246, 2017.

[9] B. Benhala, et al., "Optimal Design of Second Generation Current Conveyors by the Artificial Bee Colony Technique," International Conference on Intelligent Systems and Computer Vision, Fez, Morocco, pp. 1-5, 2015.

[10] H. Hardiansyah, "Solving economic dispatch problem with valve-point effect using a modified ABC algorithm," International Journal of Electrical and Computer Engineering (IJECE), vol/issue: 3(3), pp. 377-85, 2013.

[11] D. Karaboga, "An idea based on honey bee swarm for numerical optimization," Tech. Rep. TR06, Erciyes University, Engineering Faculty, Computer Engineering Department, 2005.

[12] D. Luong, et al., "Artificial bee colony algorithm for solving optimal power flow algorithm," The scientific world journal, vol/issue: 2013(9), 2013.

[13] C. Feng, et al., "Feed-forward neural network optimized by hybridization of PSO and ABC for abnormal brain detection," Int. J. Imaging Syst. Technol., vol. 25, pp. 153-164, 2015.

[14] C. P. Yue, et al., "A Physical model for planar spiral inductors on silicon," IEEE International Electron Devices Meeting (IEDM) Technical Digest, pp. 155-158, 1996.

[15] V. P. Durev, et al., "Parameter Extraction of Geometry Dependent RF Planar Inductor Model," Mixed Design of Integrated Circuits and Systems (MIXDES), 2010 Proceedings of the 17th International Conference. IEEE, pp. 420-424, 2010.

[16] K. Okada, et al., "Modeling and optimization of on-chip spiral inductor in S-parameter domain," 2004 Int. Symp. Circuits and Systems, vol. 5, pp. 153-156, 2004.

[17] J. E. Post, "Optimizing the Design of Spiral Inductors on Silicon," IEEE Trans. On Circuits and Systems - II: Analog and Digital Signal Processing, vol/issue: 47(1), pp. 15-17, 2000.

[18] V. P. Durev, et al., "Analysis, Model Parameter Extraction and Optimization of Planar Inductors Using MATLAB," pp. 426, 2010.

[19] S. Mohan, et al., "Simple Accurate Expressions for Planar Spiral Inductances," IEEE Journal of Solid-State Circuits, vol/issue: 34(10), pp. 1419-1424, 1999.

[20] X. Jin, "Optimization of Short-Channel RF CMOS Low Noise Amplifiers by Geometric Programming," Electrical Engineering Theses, 2012.

[21] J. Aguilera and R. Berenguer, "Design and Test of Integrated Inductors for RF Applications," Kluwer Academic Publishers, 2004.

[22] Momentum, ADS 2002, “Agilent Technologies,” EEsof division, Santa Rosa, CA, 2006.

[23] J. Craninckx and M.S. J. Steyaert, "A 1.8-GHz low-phase-noise CMOS VCO using optimized hollow spiral inductors," IEEE Journal of solid-state circuits, vol/issue: 32(5), pp. 736-744, 1997.

[24] A. M. Niknejad, "Calculation of Eddy Current Losses," Design, Simulation and Applications of Inductors and Transformers for Si RF ICs. The International Series in Engineering and Computer Science, Springer, Boston, MA, vol. 586, 2000.

[25] Y. S. Choi and J. B. Yoon, "Experimental analysis of the effect of metal thickness on the quality factor in integrated spiral inductors for RF ICs," IEEE Electron Device Letters, vol/issue: 25(2), pp. 76-79, 2004.

\section{BIOGRAPHIES OF AUTHORS}

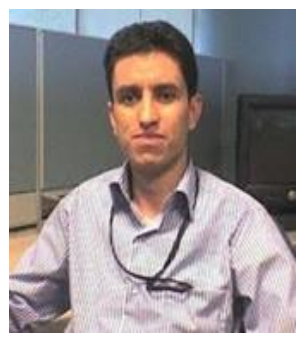

Hamid Bouyghf was born in Errachidia, in Morocco in 1982. He received the Engineer's degree in Microelectronics and telecommunications systems from FST- Fez in 2007. He is currently working towards the $\mathrm{PhD}$ degree in electronic engineering in Laboratory SSDIA ENSET Mohammedia. He interested in design and optimization of RF and Analog integrated circuits using metaheuristic algorithms. He is now a professor at Electrical Engineering Department in High School of Technology, Moulay Ismail UniversityMeknes-Morocco. 


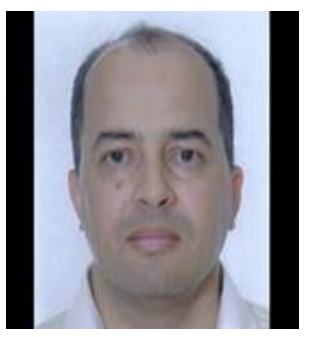

Bachir Benhala was born in Morocco in 1970. He received the teaching degree in Electronic Engineering in 1992 from the ENSET of Mohammedia (Morocco). In 2007, he received his Master's from the Faculty of Science and Technology (FST) of Fez, and his $\mathrm{PhD}$ degree in 2013 in Electronics and Microelectronics. He is currently an Professor Hability (HDR) at the Faculty of Sciences of University of Moulay Ismail in Meknes, Morocco. His research interests include metaheuristic optimization techniques, analog design automation, and digital/analog VLSI architectures.

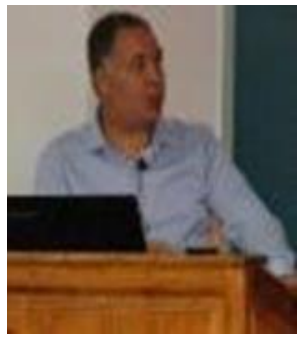

Abdelhadi Raihani has born in 1968 at El Jadida, Morocco. He is now a teacher of Electronics and researcher at ENSET Institute. His research is focused on parallel architectures and associated treatments. Recently, he worked on Wind Energy. Received the B.S. degree in Electronics in 1987 and the M.S. degree in Applied Electronics in 1991 from the ENSET Institute, Mohammedia, Morocco. He received the DEA diploma in information processing from the Ben M'sik University of Casablanca in 1994. He received the Doctorate diploma in Application of Parallel Architectures in image processing from the Ain Chok University of Casablanca in 1998. 